\title{
Selvrapportert fysisk aktivitet i 1980- og 1990-årene - Helseundersøkelsene i Nord-Trøndelag (HUNT)
}

\author{
Nanna Kurtze ${ }^{1}$, Kjell Terje Gundersen ${ }^{2}$ og Jostein Holmen ${ }^{1}$ \\ ${ }^{1}$ HUNT forskningssenter, Institutt for samfunnsmedisin, NTNU, Neptunveien 1, 7650 Verdal \\ ${ }^{2}$ Høgskolen i Nord-Trøndelag, Avd. Larerutdanning, Levanger \\ Korrespondanse: Nanna Kurtze, SINTEF Unimed, Postboks 124 Blindern, 0314 Oslo \\ Telefon: 22067438 Telefax: 22067909 E-post: nanna.kurtze@sintef.no
}

\begin{abstract}
SAMMENDRAG
Bakgrunn: Betydningen av fysisk aktivitet i det forebyggende og helsefremmende arbeidet er vel dokumentert. Det er imidlertid en økende bekymring for at nordmenn er blitt mindre fysisk aktive. Selv om det er en rekke indisier på at den fysiske aktivitet er lavere enn før er datagrunnlaget spinkelt. Hensikten med denne artikkelen er å studere utviklingen av selvrapportert fysisk aktivitet blant voksne over en 11årsperiode, fordelt på kjønn og aldersgrupper i Helseundersøkelsene i Nord-Trøndelag. Studien problematiserer måling av selvrapportert fysisk aktivitet fra hver av undersøkelsene der spørsmålsettene er forskjellige. Dette gjør det vanskelig å jevnføre data. Bruk av ulike målemetoder ved befolkningsundersøkelser er ikke bare et norsk, men også et internasjonalt problem.

Metode: Studien bygger på data fra to store befolkningsundersøkelser i Nord-Trøndelag, HUNT 1 (1984-86) med svarprosent på 88 ( $\mathrm{N}=74$ 994) og HUNT 2 (1995-97) med 71\% ( $\mathrm{N=66} 140)$.

Resultat: Resultatene fra HUNT 1 og HUNT 2, dikotomisert i inaktive og aktive viser at det er færre fysisk inaktive i 1995-97 enn i 1984-86. Andelen av inaktive er høyere blant kvinner enn menn i HUNT I. I HUNT 2 var den prosentvise fordelingen mellom inaktive kvinner og menn den samme. Resultatene ses i lys av ulikheter i de to spørsmålsettene.
\end{abstract}

\section{Kurtze N, Gundersen KT, Holmen J. Self-reported physical activity in the Nord-Trøndelag Health Study (HUNT). Nor J Epidemiol 2003; 13 (1): 171-176.}

\section{ENGLISH SUMMARY}

Background: Physical activity promotes health-related fitness and positively influences health status, quality of life and longevity. The increasing prevalence of obesity and probably decrease in physical activity among children and adults are of great concern. The objectives of this article is to study the development of self reported physical activity by sex and age among grown-ups in The Nord-Trøndelag Health Study 1984-86 (HUNT 1) and 1995-97 (HUNT 2). Different methods have been used to assess physical activity in the two studies, as well as in Norway and internationally. Validity and reliability considerations justify conclusive results.

Material and methods: HUNT $1(\mathrm{~N}=85$ 125) and HUNT $2(\mathrm{~N}=92$ 936) invited the entire population aged $\geq 20$ years. The participation rate in HUNT 1 was $88 \%$ ( $\mathrm{N}=74$ 994) and HUNT $271 \%(\mathrm{~N}=66140)$.

Results: Trivariate results when dichotomising in no activity and activity indicate a decrease in number of physically inactive in all age groups during a period of eleven years. The proportion of inactive is higher among women compared to men in HUNT 1, but equal in HUNT 2. However, the questionnaires in these studies are different in assessing physical activity and indicate the difficulty of comparing physical activity across studies using different measures.

\section{INNLEDNING}

En omfattende litteratur har vist at fysisk aktivitet er gunstig for bl.a. risikoen for hjerte- og karsykdommer, diabetes, overvekt, muskel- og skjelettplager og mental helse (1). Det er påvist at forekomsten av overvekt øker, med bl.a. risiko for diabetes og andre sykdommer (2). Sedat livsførsel og usunt kosthold må ta en stor del av skylden for dette. Det er en økende bekymring for at nordmenn er blitt mindre fysisk aktive med årene (3). Bruk av flere tekniske hjelpemidler i dagliglivet, bl.a. mer bilkjøring, er pekt på som mulige årsaker. Det er også hevdet at barn er i dårligere fysisk form enn tidligere, og at en større andel rekrutter må dimitteres av tilsvarende grunn $(4,5)$. Den aerobe kapasiteten hos norske barn synes imidlertid å ha endret seg lite siden 1952, selv om det er større spredning i resultatene i dag sammenliknet med tidligere (6). Til tross for at en rekke indisier tyder på at den fysiske aktiviteten er lavere enn før i den norske befolkningen, er datagrunnlaget spinkelt $(7,8)$. En av grunnene er at det er brukt ulike målemetoder ved de ulike undersøkelsene (9). Dette gjør det vanskelig å sammenlikne data fra ulike studier. 
I Norge er det siden 1972 gjennomført en rekke store befolkningsundersøkelser der selvrapportert fysisk aktivitet har inngått. Målet med denne artikkelen er å studere selvrapportert fysisk aktivitet ved de to Helseundersøkelsene i Nord-Trøndelag, HUNT 1 (1984-86) og HUNT 2 (1995-97) og å drøfte om datasettene støtter hypotesen om at den fysiske aktiviteten er redusert i 11-årsperioden mellom de to undersøkelsene.

\section{MATERIALE OG Metode}

I HUNT 1 (1984-86) ble alle innbyggerne i NordTrøndelag 20 år og eldre invitert til å delta, og av disse deltok 74.994 (88\%). I HUNT 2 (1995-97) ble alle innbyggerne i fylket 13 år og eldre invitert til å delta. Av de som var 20 år og eldre, deltok 66.140 personer (71\%), og disse ble inkludert i denne studien.

Ved både HUNT 1 og HUNT 2 ble data innsamlet ved hjelp av spørreskjema, kliniske målinger og blodog urinprøver. Grad av fysisk aktivitet ble målt ved selvrapportering, dvs. avkryssing på et spørreskjema som inneholdt en lang rekke helserelaterte spørsmål. Skjema 1 ble tilsendt sammen med invitasjonen til helseundersøkelsen og skulle fylles ut før frammøtet. Skjema 2, som ved HUNT 1 inneholdt spørsmål om bl.a. fysisk aktivitet, ble delt ut ved frammøtet og skulle fylles ut hjemme og returneres i posten. Ved HUNT 1 ble det stilt tre spørsmål om fysisk aktivitet (figur 1), dvs. om hyppighet, intensitet og varighet. Regelmessighet eller sesongvariasjoner var prøvd inkludert ved at deltagerne skulle "ta et gjennomsnitt" for hvert spørsmål.

Figur 1. Spørsmål om mosjon ved Helseundersøkelsen i Nord-Trøndelag 1984-86 (HUNT 1).

Med mosjon mener vi at du for eksempel går tur, går på ski, svømmer eller driver trening/idrett.

$\begin{array}{lll}\begin{array}{l}\text { Hvor ofte driver du mosjon? } \\ \text { (Ta et gjennomsnitt) }\end{array} & \\ & & \\ \text { Aldri } & \square & 1 \\ \text { Sjeldnere enn en gang i uka } & \square & 2 \\ \text { En gang i uka } & \square & 3 \\ \text { 2-3 ganger i uka } & \square & 4 \\ \text { Omtrent hver dag } & \square & 5\end{array}$

Dersom du driver slik mosjon så ofte som en eller flere ganger i uka: Hvor hardt mosjonerer du? (Ta et gjennomsnitt)

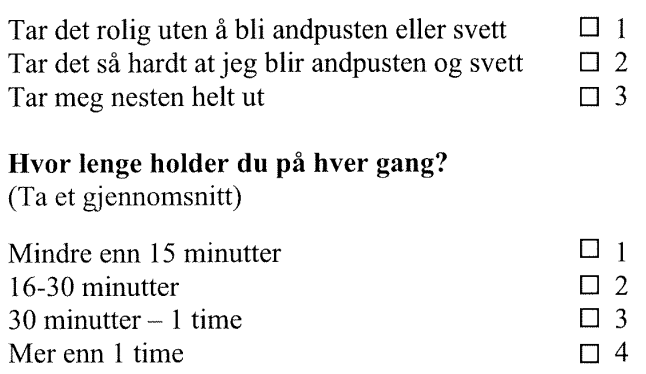

Ved HUNT 2 var spørsmålene om fysisk aktivitet inkludert i skjema 1, dvs. det skjemaet som ble tilsendt og som ble innlevert i utfylt stand ved frammøtet. Det ble denne gangen stilt to spørsmål om fysisk aktivitet (figur 2). Disse spørsmålene hadde de samme tre dimensjonene, dvs. hyppighet, varighet og intensitet, som i HUNT 1, men de var nå innbakt i hvert av de to spørsmålene om henholdsvis "lett aktivitet" og "hard fysisk aktivitet". Sesongvariasjonen var prøvd innebygget ved at deltakerne skulle ta "et ukentlig gjennomsnitt for året”.

Figur 2. Spørsmål om fysisk aktivitet brukt ved Helseundersøkelsen i Nord-Trøndelag 1995-97 (HUNT 2). Spørsmålene er også brukt i de andre CONOR-undersøkelsene.

\begin{tabular}{|c|c|c|c|c|}
\hline \multicolumn{2}{|c|}{ Arbeidsveg regnes som fritid. } & \multicolumn{2}{|c|}{ limer pr. uke } & \multirow[b]{2}{*}{$\begin{array}{c}3 \text { og mer } \\
\square\end{array}$} \\
\hline $\begin{array}{l}\text { Lett aktivitet (ikke } \\
\text { svett/andpusten/) }\end{array}$ & $\begin{array}{c}\text { Ingen } \\
\square\end{array}$ & $\begin{array}{c}\text { Under } 1 \\
\square\end{array}$ & $\begin{array}{c}1-2 \\
\square\end{array}$ & \\
\hline $\begin{array}{l}\text { Hard fysisk aktivitet } \\
\text { (svett/andpusten) }\end{array}$ & $\begin{array}{c}\square \\
1\end{array}$ & $\begin{array}{l}\square \\
2\end{array}$ & $\begin{array}{l}\square \\
3\end{array}$ & $\begin{array}{l}\square \\
4\end{array}$ \\
\hline
\end{tabular}

En forutsetning for å sammenlikne fysisk aktivitet $\mathrm{i}$ HUNT 1 og HUNT 2 er at spørsmålene i begge undersøkelsene måler det samme, dvs. uttrykker noen felles mål. Vi fant bare ett slikt felles mål, nemlig fysisk inaktivitet. Begge spørsmålssettene skilte mellom lett aktivitet, der det ikke ble stilt krav om intensitet ("blir ikke svett/andpusten"), og hard fysisk aktivitet ("blir svett/andpusten"). Det var dermed mulig å skille ut de som rapporterte fysisk inaktivitet i begge undersøkelsene, dvs. de negative ytterpunktene i begge datasettene. Dette ble gjort på følgende måte: Ved HUNT 1 ble de som rapporterte at de "aldri" drev mosjon definert som fysisk inaktive (tabell 1a). Ved HUNT 2 ble de som rapporterte "ingen" på begge spørsmålene, dvs. de som rapporterte at de verken drev lett aktivitet eller hard fysisk aktivitet definert som fysisk inaktive (tabell 3). Vi har så sammenlignet den gruppen som ble definert som fysisk inaktive i HUNT 1 (1984-86) med de som ble definert som fysiske inaktive ved HUNT 2 (1995-97).

\section{RESULTATER}

Ved HUNT 1 (1984-86) rapporterte 13.367 personer $(21,7 \%)$ at de mosjonerte 2-3 ganger per uke og 8.181 personer $(13,3 \%)$ at de mosjonerte omtrent hver dag. En noe større andel menn $(13,8 \%)$ enn kvinner $(12,7 \%)$ rapporterte at de mosjonerte omtrent hver dag. Hele $65,2 \%$ rapporterte at de mosjonerte aldri eller en gang per uke eller sjeldnere. I de fleste gruppene var det større andel kvinner enn menn (tabell 1a). I HUNT 1 rapporterte også $9504(45,4 \%)$ av mennene og 6581 (31\%) av kvinnene at de mosjonerte så hardt at de ble andpusten og svett (tabell $1 \mathrm{~b}$ ). Totalt var det $16,5 \%$ 
som holdt på mer enn en time hver gang (tabell 1c). Til sammen 8.804 personer $(13,7 \%$ menn og $14,8 \%$ kvinner) rapporterte at de "aldri" mosjonerte, og ble altså definert som fysisk inaktive i vår studie (tabell 1a).

Ved HUNT 2 rapporterte en større andel kvinner enn menn at de drev lett aktivitet 1-2 timer per uke (39,2\% kvinner mot 35,1\% menn (tabell 2a). Både blant de som rapporterte at de drev lett aktivitet 3 timer eller mer og de som rapporterte under 1 time eller ingen aktivitet $\mathrm{i}$ det hele tatt, var det imidlertid overvekt av menn (tabell 2a). Til sammen 2327 menn $(8,3 \%)$ og 2525 kvinner $(8,3 \%)$ rapporterte at de drev "ingen" aktivitet i det hele tatt, og ble dermed definert som fysisk inaktive (tabell 3). Ved HUNT 1 var andelen inaktive menn lavest i aldersgruppen 40-49 år, mens den var høyere både blant de yngre og de eldre, og høyest i aldersgruppen 80 år + (tabell 3). Blant kvinnene økte andelen inaktive gradvis med alderen helt fra yngste aldersgruppe (tabell 3).

Ved HUNT 2 var andelen inaktive relativt stabilt opp til 60-69 år for menn og opp til 50-59 år for kvinner, for deretter å øke gradvis (tabell 3 og figur 3). I alle aldersgrupper for begge kjønn var det en nedgang $i$ andelen som rapporterte fysisk inaktivitet ved HUNT 2 i forhold til HUNT 1, dvs. 11 år tidligere.

\section{DISKUSJON}

Resultatene viser altså at en mindre andel rapporterte fysisk inaktivitet ved HUNT 2 som foregikk i perioden 1995-97 sammenlignet med HUNT 1 som ble gjennomført i perioden 1984-86. Dette gjaldt for begge kjønn og alle aldersgrupper, selv om endringene var størst blant kvinnene. Resultatene var altså motsatt av de en kunne forvente ut fra den pågående debatten om utviklingen av den fysiske aktiviteten og årsakene til den generelle vektøkningen i befolkningen (10). Spørsmålene som ble stilt $\mathrm{i}$ de to undersøkelsene var ikke identiske, og det er derfor grunn til å drøfte om våre data fra HUNT gjenspeiler en reell utvikling, eller om de kan reflektere systematiske målefeil.

Da målemetodene har vært ulike, er det ikke lett å sammenligne resultatene fra HUNT med andre norske undersøkelser (11). Ved MMI's landsrepresentative undersøkelse av befolkningen over 15 år i 1985 oppga $14 \%$ at de "aldri" trente/mosjonerte (12), mens tilsvarende tall i HUNT 1 (1984-86) var 14,3\%. Ved Levekårsundersøkelsen i 1995 (13) rapporterte $19 \%$ at de drev "ingen" trening eller mosjon, og det var ingen forskjell mellom kjønnene. Tilsvarende tall for HUNT 2 definert som inaktive var 8,3\% for begge kjønn.

Tabell 1a. "Hvor ofte driver du mosjon?" Helseundersøkelsen i Nord-Trøndelag 1984-86 (HUNT 1) (Med mosjon mener vi at du f.eks. går på tur, går på ski, svømmer eller driver trening/idrett).

\begin{tabular}{|c|c|c|c|c|c|c|}
\hline & \multicolumn{2}{|c|}{ Menn } & \multicolumn{2}{|c|}{ Kvinner } & \multicolumn{2}{|c|}{ Total } \\
\hline & Antall & $\%$ & Antall & $\%$ & Antall & $\%$ \\
\hline Aldri & 4150 & 13,7 & 4654 & 14,8 & 8804 & 14,3 \\
\hline Mindre enn 1gang per uke & 8410 & 27,8 & 8108 & 25,8 & 16518 & 26,8 \\
\hline 1 gang per uke & 6963 & 23,0 & 7899 & 25,1 & 14862 & 24,1 \\
\hline 2-3 ganger per uke & 6571 & 21,7 & 6796 & 21,6 & 13367 & 21,7 \\
\hline Omtrent hver dag & 4190 & 13,8 & 3991 & 12,7 & 8181 & 13,3 \\
\hline Totalt & 30284 & 100 & 31448 & 100 & 61732 & 100 \\
\hline
\end{tabular}

Tabell 1b. "Dersom du driver slik mosjon så ofte som en eller flere ganger i uka: Hvor hardt mosjonerer du?" Helseundersøkelsen i Nord-Trøndelag 1984-86 (HUNT 1).

\begin{tabular}{|c|c|c|c|c|c|c|}
\hline & \multicolumn{2}{|c|}{ Menn } & \multicolumn{2}{|c|}{ Kvinner } & \multicolumn{2}{|c|}{ Totalt } \\
\hline & Antall & $\%$ & Antall & $\%$ & Antall & $\%$ \\
\hline Tar det rolig uten å bli andpusten eller svett & 10381 & 49,6 & 14371 & 67,6 & 24752 & 58,7 \\
\hline Tar det så hardt at jeg blir andpusten og svett & 9504 & 45,4 & 6581 & 31,0 & 16085 & 38,1 \\
\hline Tar meg nesten helt ut & 1043 & 5,0 & 305 & 1,4 & 1348 & 3,2 \\
\hline Totalt & 20928 & 100 & 21257 & 100 & 42185 & 100 \\
\hline
\end{tabular}

Tabell 1c. “Hvor lenge holder du på hver gang?” Helseundersøkelsen i Nord-Trøndelag 1984-86 (HUNT 1).

\begin{tabular}{lcccccccc}
\hline & \multicolumn{2}{c}{ Menn } & & \multicolumn{2}{c}{ Kvinner } & & \multicolumn{2}{c}{ Totalt } \\
\cline { 2 - 3 } & Antall & $\%$ & & Antall & $\%$ & & Antall & $\%$ \\
\hline Mindre enn 15 minutter & 2121 & 10,0 & & 2772 & 13,0 & & 4893 & 11,5 \\
16-30 minutter & 6090 & 28,8 & & 8048 & 37,7 & & 14138 & 33,2 \\
30 minutter-1 time & 7951 & 37,6 & & 8530 & 39,9 & & 16481 & 38,7 \\
Mer enn 1 time & 5012 & 23,7 & & 2012 & 9,4 & & 7024 & 16,5 \\
\hline Totalt & 21174 & 100,1 & & 21362 & 100 & & 42536 & 100 \\
\hline
\end{tabular}


Vaage oppga at $28 \%$ utførte "aldri trening eller mosjon" i løpet av et år. Han mente at på siste del av 1990tallet var kvinner mer aktive mosjonister enn menn (14), og at inaktiviteten økte med alderen (11), slik som HUNT-data også viser. Longitudinelle studier har vist at økende forekomst av fedme kan tilbakeføres til sedat livsførsel (15-18). I andre norske studier varierer imidlertid andelen inaktive fra 14\% til 50\% (8). Store undersøkelser gjennomført av Norsk Monitor 1999 (upubliserte data) og Norkost 1993 og 1997 (8), benyttet kategorien "aldri/sjeldnere enn" et gitt antall ganger per uke, per 14. dag eller per måned. Et eksempel er Søgaard og medarbeidere (11) som rapporterte at mer enn en av tre voksne nordmenn var inaktive, dvs. de mosjonerte sjeldnere enn ukentlig.

Validering av selvrapportert fysisk aktivitet har vist at en todeling ved bruk av et spørsmål, slik det er gjort i egen studie, kan være mer valid enn å operere med en finere kategorisering $(19,20)$. I egen studie ble det ikke stilt krav til intensitet $\mathrm{i}$ de to undersøkelsene. Fysisk belastende aktiviteter så vel som lettere aktiviteter kunne inkluderes.

Bruk av ulike målemetoder ved slike undersøkelser er ikke bare et norsk, men i like stor grad et internasjonalt problem (21). Sammenlikninger kompliseres ytterligere fordi det brukes både ulike målenivåer, begreper, dimensjoner og kategorier. Ved de store norske helseundersøkelsene er det brukt et mangfold av spørsmål for å måle nivået av fysisk aktivitet (12,22-27). For de enkelte studiene kan spørsmålene likevel gi verdifull informasjon, men sammenligninger og trendanalyser blir vanskelige.

Tabell 2a. "I Fritida: Hvordan har din fysiske aktivitet vært det siste året? Tenk deg et ukentlig gjennomsnitt for året. Arbeidsveg regnes som fritid" (Lett aktivitet, dvs. ikke svett/andpusten). Helseundersøkelsen i Nord-Trøndelag 1995-97 (HUNT 2).

\begin{tabular}{|c|c|c|c|c|c|c|}
\hline \multirow{2}{*}{$\begin{array}{l}\text { Lett aktivitet (ikke svett/andpusten) } \\
\text { Timer per uke }\end{array}$} & \multicolumn{2}{|l|}{ Menn } & \multicolumn{2}{|c|}{ Kvinner } & \multicolumn{2}{|l|}{ Totalt } \\
\hline & Antall & $\%$ & Antall & $\%$ & Antall & $\%$ \\
\hline Ingen & 2456 & 9,6 & 2541 & 8,8 & 4997 & 9,2 \\
\hline Under 1 time & 4712 & 18,5 & 4966 & 17,2 & 9678 & 17,8 \\
\hline 1-2 timer & 8966 & 35,1 & 11322 & 39,2 & 20288 & 37,3 \\
\hline 3 timer eller mer & 9374 & 36,7 & 10073 & 34,9 & 19447 & 35,7 \\
\hline Totalt & 25508 & 100 & 28902 & 100 & 54410 & 100 \\
\hline
\end{tabular}

Tabell 2b. "I Fritida: Hvordan har din fysiske aktivitet vært det siste året? Tenk deg et ukentlig gjennomsnitt for året. Arbeidsveg regnes som fritid”. (Hard aktivitet, dvs. svett/andpusten). Helseundersøkelsen i Nord-Trøndelag 1995-97 (HUNT 2).

\begin{tabular}{|c|c|c|c|c|c|c|}
\hline \multirow{2}{*}{$\begin{array}{l}\text { Hard aktivitet (svett/andpusten) } \\
\text { Timer per uke }\end{array}$} & \multicolumn{2}{|r|}{ Menn } & \multicolumn{2}{|c|}{ Kvinner } & \multicolumn{2}{|r|}{ Totalt } \\
\hline & Antall & $\%$ & Antall & $\%$ & Antall & $\%$ \\
\hline Ingen & 7665 & 33,6 & 10409 & 45,9 & 18074 & 39,7 \\
\hline Under 1 time & 6067 & 26,6 & 5694 & 25,1 & 11761 & 25,8 \\
\hline $1-2$ timer & 5236 & 22,9 & 4748 & 20,9 & 9984 & 21,9 \\
\hline 3 timer eller mer & 3877 & 17,0 & 1827 & 8,1 & 5704 & 12,5 \\
\hline Totalt & 22845 & 100 & 22678 & 100 & 45523 & 100 \\
\hline
\end{tabular}

Tabell 3. Andelen definert som fysisk inaktive ved HUNT 1 og HUNT 2 fordelt på alder og kjønn. Ved HUNT 1 ble de som svarte "aldri” på spørsmålet: "Hvor ofte driver du mosjon" definert som fysisk inaktive. Ved HUNT 2 ble de som svarte "ingen lett aktivitet (ikke svett/andpusten)" og "ingen hard fysisk aktivitet (svett/andpusten) på spørsmålet: "Hvordan har din fysiske aktivitet i fritida vært det siste året?” definert som fysisk inaktive. Prosent og antall av hver aldersgruppe.

\begin{tabular}{|c|c|c|c|c|c|c|c|c|c|c|c|c|}
\hline \multirow[b]{3}{*}{ Alder } & \multicolumn{4}{|c|}{ Menn } & \multicolumn{4}{|c|}{ Kvinner } & \multicolumn{4}{|c|}{ Totalt } \\
\hline & \multicolumn{2}{|c|}{ HUNT 1} & \multicolumn{2}{|c|}{ HUNT 2} & \multicolumn{2}{|c|}{ HUNT 1} & \multicolumn{2}{|c|}{ HUNT 2} & \multicolumn{2}{|c|}{ HUNT 1} & \multicolumn{2}{|c|}{ HUNT 2} \\
\hline & $\%$ & Antall & $\%$ & Antall & $\%$ & Antall & $\%$ & Antall & $\%$ & Antall & $\%$ & Antall \\
\hline $20-29$ & 13,4 & 615 & 7,3 & 284 & 7,4 & 335 & 3,6 & 168 & 10,4 & 950 & 5,3 & 452 \\
\hline $30-39$ & 10,0 & 643 & 7,4 & 393 & 7,8 & 503 & 5,2 & 308 & 8,9 & 1146 & 6,2 & 701 \\
\hline $40-49$ & 9,4 & 461 & 7,4 & 470 & 9,0 & 455 & 5,1 & 346 & 9,2 & 916 & 6,2 & 816 \\
\hline $50-59$ & 12,8 & 591 & 7,2 & 367 & 13,1 & 622 & 6,0 & 314 & 13,0 & 1213 & 6,6 & 681 \\
\hline $60-69$ & 15,9 & 834 & 8,4 & 318 & 16,3 & 873 & 11,2 & 412 & 16,1 & 1707 & 9,8 & 730 \\
\hline $70-79$ & 18,5 & 632 & 11,7 & 329 & 28,7 & 1117 & 19,9 & 561 & 23,9 & 1749 & 15,8 & 890 \\
\hline $80+$ & 33,9 & 373 & 21,5 & 166 & 51,3 & 749 & 38,7 & 416 & 43,8 & 1122 & 31,5 & 582 \\
\hline Totalt & 13,7 & 4149 & 8,3 & 2327 & 14,8 & 4654 & 8,3 & 2525 & 14,3 & 8803 & 8,3 & 4852 \\
\hline
\end{tabular}




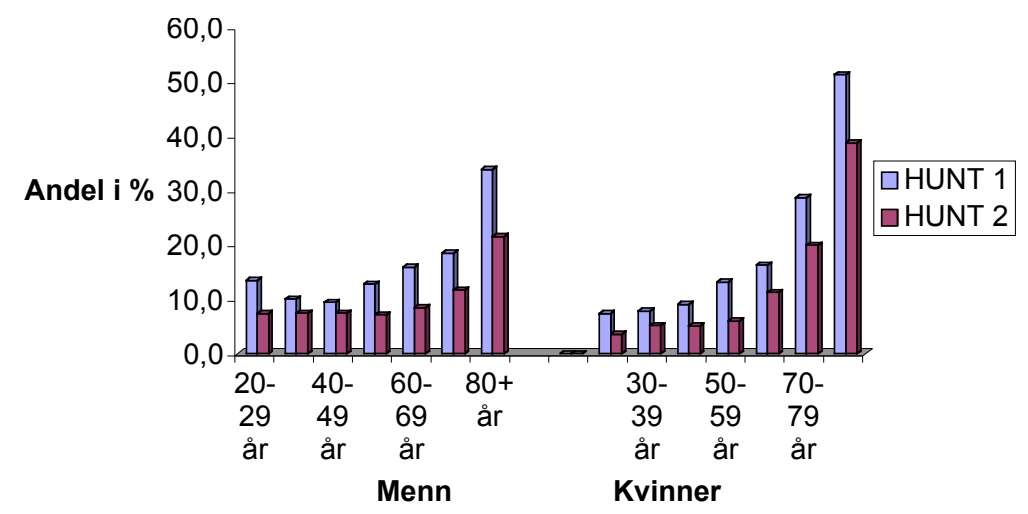

Figur 3. Fysisk inaktivitet i HUNT 1 og HUNT 2 i årene 1984-86 til 1995-97 fordelt på kjønn og aldersgrupper.

\section{Ulike begreper}

Det kan tenkes at begrepet "mosjon" som ble brukt ved HUNT 1 kunne bli oppfattet å være mer anstrengende enn begrepet "fysisk aktivitet" brukt ved HUNT 2, særlig av de mer voksne. Fysisk aktivitet omfatter gjerne både mosjon og trening. Ved HUNT 1 var det imidlertid ikke differensiert mellom mosjon på fritiden og mosjon knyttet til arbeid. Det betyr at HUNT 1deltakerne i tilfelle ville forutsette relativt større fysisk innsats før de ville krysse av at de mosjonerte f.eks. en gang i uka, mens HUNT 2-deltakerne kanskje kunne krysse av for lett fysisk aktivitet 1-2 ganger i uka for tilsvarende innsats. Dette kunne dermed føre til at en større andel ble kategorisert som inaktive ved HUNT 1 enn ved HUNT 2. Imidlertid var begrepet mosjon ved HUNT 1 operasjonalisert i ulike typer aktiviteter, også lette aktiviteter som f.eks. å gå tur. En skulle dermed forvente at de som rapporterte at de "aldri" drev slik mosjon, virkelig var inaktive, tilsvarende de som ble definert som inaktive ved HUNT 2. Ut fra dette mener vi det er mulig å studere endringene i 11-årsperioden mellom HUNT 1 og HUNT 2.

\section{Ulike dimensjoner}

For å få et valid mål på det fysiske aktivitetsnivået bør fire dimensjoner inkluderes: Hyppighet, dvs. hvor ofte vedkommende driver fysisk aktivitet, varighet, dvs. hvor lenge den varer hver gang, intensitet, dvs. hvor hard aktiviteten er, og regelmessighet, dvs. hvor mye aktiviteten varierer med sesong, for eksempel mellom sommer- og vinterhalvåret (28).

Ved HUNT 1 ble nettopp spørsmålene om hyppighet benyttet. Spørsmålene om lett aktivitet og hard fysisk aktivitet i HUNT 2 hadde kategorien "ingen" som svaralternativ. "Ingen" tilsvarer dermed "aldri" for hyppighetsvariabelen. Begge kategorier kan bety "aldri noen fysisk aktivitet" eller "ingen form for fysisk aktivitet" og vil trolig være sammenliknbare.

Verken ved HUNT 1 eller HUNT 2 var sesongvariasjoner direkte inkludert. Dette er en viktig dimensjon som ofte har vært utelatt i de andre store befolkningsundersøkelsene. Det er velkjent at den fysiske aktiviteten kan variere med årstidene, slik at mange er aktive $\mathrm{i}$ sommerhalvåret men mer inaktive $\mathrm{i}$ det kalde vinterhalvåret. Svarene kan dermed preges av hvilken årstid undersøkelsene er foretatt. Ved HUNT 1 ble deltakerne bedt om å "ta et ukentlig gjennomsnitt for året”, og dette kan korrigere noe for sesongvariasjonene, selv om retrospektive rapporteringer over så lang tid som et år kan være upresise.

Ved måling av fysisk aktivitet bør det også skilles mellom fysisk aktivitet på fritiden og fysisk aktivitet $\mathrm{i}$ arbeid, og dessuten om vegen til og fra arbeidet inngår i målingen.

Ved HUNT 1 ble det ikke skilt mellom mosjon på fritiden og mosjon knyttet til arbeid. Det var også usikkert om fysisk aktivitet ved transport til og fra arbeid skulle inkluderes. Ved HUNT 2 var det presisert at det var snakk om fysisk aktivitet i fritiden, og at reise til og fra arbeidet skulle regnes som fritid. Imidlertid når det gjelder å bruke fysisk aktivitet som forklaringsvariabel er det fullt brukbart.

\section{Ulike kategorier}

Valideringsstudier har vist at en todeling av data på den måten det er gjort her, kan gi mer gyldige resultat enn en finere inndeling i kategorier, eksempelvis i et gitt antall nivåer eller timer aktivitet. Andre studier har vist at hyppighetsvariabelen, dvs. hvor ofte aktiviteten forekommer, f.eks. relatert til siste uke, gir god indikasjon på aktivitetsnivået, dersom den også todeles $\mathrm{i}$ "aktivitet" og "ingen aktivitet" (29).

\section{KONKLUSJON}

Resultatene fra de to store befolkningsundersøkelsene HUNT 1 og HUNT 2 gir ingen indikasjon på at en større andel av befolkningen er blitt inaktive i 11årsperioden mellom 1984-86 og 1995-97, slik vi hadde ventet å finne. Data tyder faktisk på at andelen inaktive er blitt færre, men på grunn av ulike målemetoder vil vi være forsiktige med å trekke en sikker konklusjon. Ved HUNT 1 (1984-86) var det størst andel inaktive kvinner, men i 1995-97 var kjønnsforskjellene visket ut. Dette kan stemme med andre undersøkelser som har vist at flere kvinner ble fysisk aktive i denne perioden (12).

Fremtidige befolkningsundersøkelser bør sørge for å standardisere målemetodene bedre, bl.a. ved å bruke 
samme spørsmålsformulering og samme begreper. Spørsmålene bør også eksplisitt inkludere eller ekskludere arbeidsveg og fysisk aktivitet $\mathrm{i}$ arbeid. Bare ved å bruke et godt og standardisert måleinstrument kan endringer $\mathrm{i}$ det fysiske aktivitetsnivået $\mathrm{i}$ den norske befolkningen følges over tid på en gyldig og pålitelig måte.
Helseundersøkelsen i Nord-Trøndelag (HUNT 1 og 2) er et samarbeid mellom HUNT forskningssenter, Det medisinske fakultet, Norges teknisk-naturvitenskapelige universitet (NTNU), Verdal, Nasjonalt Folkehelseinstitutt og Nord-Trøndelag fylkeskommune.

\section{REFERANSER}

1. Physical activity, Fitness, and Health International Proceedings and Consensus Statement. Champaign: Human Kinetics Publishers, 1994.

2. Midthjell K, Krüger $\varnothing$, Holmen J, Tverdal A, Claudi T, Bjørndal A, et al. rapid changes in the prevalence of obesity and known diabetes in an adult Norwegian population. Diabetes Care 1999; 22: 1813-1820.

3. Kaggestad J. Dårligere tider gir dårlig helse. Aftenposten (morgenutgave) 19. november: 52.

4. Hole A. Leken slår ut slitet. Aftenposten (morgenutgave) 22. april 1996: 13.

5. Kirkeboen SE. Fysisk forfall. Svakere soldater. Aftenposten (morgenutgave) 23. november 1996: 25.

6. Fredriksen PM, Thaulow E, Nystad W, Ingjer F. Aerob kapasitet hos barn og unge - nordiske resultater gjennom 45 år. Tidsskriftet Nor Lageforen 1998; 20: 3106-3110.

7. Arnesen E. Hvor ble det av leken? 9. 1996. Oslo: Sosial- og helsedepartementet.

8. Statens råd for ernæring og fysisk aktivitet. Fysisk aktivitet og helse Kartlegging. rapport nr. 1. 2001. Oslo: SEF.

9. LaPorte RE, Montoye HJ, Caspersen CJ. Assessment of physical activity in epidemiologic research: problems and prospects. Public Health Rep 1985; 100: 131-146.

10. Statens råd for ernæring og fysisk aktivitet. 1 VEKT - HELSE. Rapport nr. 1, 1-170. 2002. Oslo: SEF.

11. Søgaard AJ, Bø K, Klungland M, Jacobsen BK. En oversikt over norske studier - hvor mye beveger vi oss i fritiden? Tidsskr Nor Laegeforen 2000; 28: 3439-3446.

12. Markeds- og Media Instituttets landsrepresentative undersøkelse av befolkningen over 15 år. 1997. Norsk Monitor.

13. Helseundersøkelsen 1995. Oslo: 1996.

14. Vaage OF. Trening og mosjon: Kvinner og menn er like aktive. Samfunnsspeilet, Tidsskrift for levekår og livsstil 1999.

15. Griffiths M, Payne PR, Stunkard AJ, Rivers JP, Cox M. Metabolic rate and physical development in children at risk of obesity. Lancet 1990; 336: 76-78.

16. Haapanen Nea. Association between leisure time physical activity, related energy expenditure and body composition: a gender difference. Int J Obes Rel Metab Disord 1997; 21: 288-296.

17. Williamson DF, Madans J, Anda RF, Kleinman JC, Kahn HS, Byers T. Recreational physical activity and tenyear weight change in a US national cohort. Int J Obes Relat Metab Disord 1993; 17: 279-286.

18. Williamson DF. Dietary intake and physical activity as "predictors" of weight gain in observational, prospective studies of adults. Nutr Rev 1996; 54: 101-109.

19. Gionet NJ, Godin G. Self-reported exercise behavior of employees: a validity study. J Occup Med 1989: 31: 969-973.

20. Schechtman KB, Barzilai B, Rost K, Fisher EB Jr. Measuring physical activity with a single question. Am $J$ Public Health 1991: 81: 771-773.

21. Lamb KL, Brodie DA. The assessment of physical activity by leisure-time physical activity questionnaires. Sports Med 1990; 10: 159-180.

22. Helseundersøkelse 1975. Oslo: Statistisk sentralbyrå, 1975.

23. Helseundersøkelse 1985. Oslo-Kongsvinger: Statistisk sentralbyrå, 1985.

24. Helseundersøkelsen 1995. Oslo-Kongsvinger: Statistisk sentralbyrå, 1995.

25. Helseundersøkelsene i Østfold 1985 og 1988 og i Aust-Agder 1986 og 1989. Oslo: Statens helseundersøkelser, 1997.

26. Samordnet levekårsundersøkelse 1997 - tverrsnittsundersøkelsen. Dokumentasjonsrapport. 98/34. OsloKongsvinger: Statistisk sentralbyrå, 1998.

27. Temaroterende levekårsundersøkelse 1998. Oslo-Kongsvinger: Statistisk Sentralbyrå, 1998.

28. Strømme SB, Ingjer F. Virkningen av regelmessig fysisk aktivitet på hjertet og kretsløpsystemet. Tidsskr Nor Lageforen 1980; 100: 747-752.

29. Ainsworth BE, Jacobs DR Jr, Leon AS. Validity and reliability of self-reported physical activity status: the Lipid Research Clinics questionnaire. Med Sci Sports Exerc 1993; 25: 92-98. 